10. Бермус А.Г. Проблемы и перспективы реализации компетентностного подхода в образовании [Электронный ресурс] // Интернет-журнал «Эйдос», 2005. 10 сентября. - http://eidos.ru/journal/2005/091012.htm.

11. Равен Дж. Компетентностность в современном обществе. Выявление, развитие и реализация. М.: Когито-центр, 2002. 394 с.

12. Winterton J., Delamare - Le Deist F., Stringfellow E. Typology of knowledge, skills and competences: clarification of the concept and prototype. Thessaloniki: CEDEFOP, 2006. 140 p.

13. Whiddett S., Hollyford S. Competences // Chartered Institute of Personnel and Development. London. 2007. P. 42.

14. Философский словарь / под ред. И.Т. Фролова. М., 1991. С. 267-268.

15. Ожегов С.И. Словарь русского языка: ок. 57000 слов / под ред. Н.Ю. Шведовой. 15-е изд. М.: Рус. яз., 1984. 816 с.

16. Бабанский Ю.К. Проблемы эффективности педагогических исследований: Дидактический аспект. М.: Педагогика, 1982. 192 с.

17. Заболотский В.П., Оводенко А.А., Степанов А.Г. Математические модели в управлении: учебное пособие. СПб.: СПбГУАП, 2001. 196 с.
18. Глинский Б.А., Грязнов Б.С., Никитин Е.А. Моделирование как метод научного познания. М.: Изд-во МГУ, 1965. 280 с.

19. Ушаков А.А. Развитие исследовательской компетентности учащихся общеобразовательной школы в условиях профильного обучения: дис. ...канд. пед. наук: 13.00.01. Майкоп, 2008. 190 с.

20. Краевский В.В. Методология научного исследования: пособие для студентов и аспирантов гуманитарных ун-тов. СПб.: СПбГУП, 2001. 211 с.

21. Щербакова Т.К. Структурно-функциональная модель содержания профессиональной деятельности учителя (на примере учителя географии): автореф. дис. ... д-ра пед. наук. М., 2005. 41 с.

22. Приказ Министерства образования и науки РФ «Об утверждении федерального государственного образовательного стандарта высшего образования по направлению подготовки 44.03.05 Педагогическое образование (с двумя профилями подготовки) (уровень бакалавриата)», от 9 февраля 2016 г. № 91 [Электронный ресурс] // Официальный интернетпортал правовой информации, № 0001201603090029. - http://pravo.gov.ru.

\title{
STRUCTURAL AND FUNCTIONAL MODEL OF THE FUTURE MATHEMATICS TEACHER'S PROFESSIONAL COMPETENCE FORMATION
} (C) 2017

Zvereva Ekaterina Yakovlevna, senior lecturer

of Informatics, Theory and Methods of Teaching Informatics Department Transbaikal State University (Chita, Russian Federation)

Abstract. In this paper the author considers a structural and functional model of the future mathematics teacher's professional competence formation through the contextual tasks of the mathematical analysis in the implementation of competence and contextual approaches in the training of bachelors majoring in «Pedagogical Education». The author analyses scientific and methodological literature on the competence approach and «Model» as the basic concept of this paper. In the research the main components of the future mathematics teacher's professional competence formation process are defined: information and methodological, subject and methodical, social and communicative, personal and valeological competences, development of which occurs in the process of solving contextual tasks of the mathematical analysis, which are subdivided into subject, interdisciplinary, practical and professional. The unity of the structural (goal, methodology, content and organization of the process, result) and the functional components of the model (stages, criteria, indicators, levels of the future mathematics teacher' professional competence formation) are described. In each structural component of the model, the content and determining moments are described in detail. The author comes to the conclusion that the developed model of the future mathematics teacher's professional competence formation can be used to develop the professional competence of the future teacher of another direction.

Keywords: model; competence approach; contextual approach; competence; training of bachelors majoring in pedagogical education; structural and functional model of future mathematics teacher' professional competence formation; pedagogical education; contextual tasks of mathematical analysis.

УДК 796.01

Статья поступила в редакцию 07.05.2017

\section{ЦЕННОСТИ ФИЗИЧЕСКОЙ КУЛЬТУРЫ: СТРУКТУРА, ХАРАКТЕРИСТИКА}

(C) 2017

Коровин Сергей Семенович, доктор педагогических наук,

профессор кафедры теории и методики спортивных дисциплин, адаптивной физической культуры и медико-биологических основ физического воспитания

Малорошвило Лилия Наилевна, кандидат педагогических наук, доцент, заведующий кафедрой физической культуры

Оренбургский государственный педагогический университет (г. Оренбург, Российская Федераичя)

Аннотащия. Целевым ориентиром разработки и обоснования создаваемых теорий, технологий и конструкций образовательных систем является сформированность культурологических характеристик личности на всех этапах непрерывного образования, отражающих ментальность общества и состояние (как результат) 
- сформированность ценностно-ориентированных «надбиологических» программ деятельности человека, знаний, умений и навыков их прикладного и творческого использования. Значимой представляется направленность системы образования на становление компонентов (их характеристик) базовой культуры личности, к которым относят нравственную, эстетическую, трудовую, гражданскую, интеллектуальную (познавательную) и физическую. В этой связи основу культурологической парадигмы реконструкции образовательных систем составляет оптимизация процессов направленного использования ценностей культуры в реальной практике формирования личности. Необходимость же гармонизации в личности ее биосоциальных характеристик предопределяет целенаправленное использование для этого в образовательной практике ценностей физической культуры, которые регламентируют содержание физкультурно-спортивной деятельности и способствуют формированию как общесоциальной, так и, главным образом, физической культуры субъекта. В настоящее время структура ценностей физической культуры может быть представлена группой материальных (тело человека, спортивный инвентарь и оборудование, спортивные сооружения, средства массовой информации, научное оборудование, средовые-естественные факторы), духовных (двигательные, интеллектуальные, педагогические, мобилизационные, интенционные) и художественных (совокупность художественных образов и произведений, отражающих ценности материальной и духовной сфер социума). Следует полагать, что оптимальное соотношение используемых ценностей физической культуры будет обеспечивать качество содержания физкультурно-спортивной деятельности и как следствие - становление основных признаков сформированности культуры обучающихся.

Ключевые слова: культура; образование; физическая культура; физическое образование; формирование личности; компоненты базовой культуры личности; физическая культура личности; структура ценностей физической культуры; характеристика материальных, духовных и художественных ценностей физической культуры; процессуальная и результативная составляющая освоенности ценностей физической культуры.

На современном этапе совершенствования системы образования в педагогическом сообществе, по сути, общепризнано - основным целевым ориентиром создаваемых теорий и технологий, конструкций образовательных систем является формирование культурологических характеристик человека на пути его восхождения к личности на всех этапах непрерывного образования, понимаемых как отражение ментальности социума, освоенности обучающимися совокупности ценностей культуры, в сущности регламентирующих содержание образования и зарегистрированных в ценностно-ориентированных «надбиологических» программах деятельности, знаниях, умениях и навыках их прикладного и творческого использования [1]. Значимой представляется также и направленность системы образования на формирование именно компонентов базовой культуры личности как отражения присвоенности ценностей нравственной, трудовой, гражданской, эстетической, интеллектуальной (познавательной) и физической культуры [2].

Таким образом, основополагающим фактором формирования личности является «культурообразующая» деятельность обучающихся по освоению ценностей культуры, которая рассматривается как форма, отражающая и определяющая качество жизни и сознания [3]; свойство и отражение функций развития общества, творческих сил и способностей человека [4; 5]; способ самореализации человека и развития его сущностных сил [6]; способ и средство деятельности человека [4, с. 86; 7]; практически все надбиологические программы человеческой деятельности и ее результаты [8, с. 1068].

Следовательно, культура как предметная деятельность человека есть фактор развития общества; выступает основным фактором создания человека культуры для его успешной социализации; является основанием для моделирования различных систем (включая, на наш взгляд, реализацию главной функции социума - образовательной) для направленного использования ценностей культуры для удовлетворения различных потребностей и развития различных способностей человека.
Такое понимание культуры есть, во-первых, отражение культурологического подхода, принятого в педагогическом сообществе и образовании и, вовторых, основание для реконструкции образовательных систем направленного использования ценностей культуры (вообще) в становлении личности и формировании ее подготовленности к конкретной (избранной) образовательной и профессиональной деятельности. К таким заключениям подвигают и рассуждения С.И. Гесена, который отмечает, что между культурой и педагогической деятельностью (читай образованием) существует полное соответствие, так как «цели педагогической деятельности совпадают с целями культуры» [9, с. 23].

При этом в ряду социокультурных ценностей, реализуемых в системе образования (физического образования, в частности) и определяющих оптимизацию процессов формирования ценностных ориентаций, системы двигательных и личностных способностей и потребностей, находятся и ценности культуры физической, которые, в свою очередь, являются общепризнанными социокультурными ценностями и присвоение которых (как целевой ориентир физического образования) есть отражение интегрального и динамичного личностного состояния - физической культуры субъекта [10-13 и др.].

В этой связи решающее значение в формировании физической культуры личности (ФКЛ) (впрочем, и сопряженных с ней видов-компонентов базовой культуры личности), принадлежит ценностям физической культуры, оптимальное соотношение которых в процессе физического образования - реальная предпосылка достижения личностно и социально востребуемого соотношения в личности ее надбиологических телесно-душевно-духовных начал, качеств и свойств как отражения сформированности социокультурной личности (как главного «продукта» образования). Таким образом, возникает необходимость системного представления и рассмотрения ценностей физической культуры, направленное использование которых оказывает социально и личностно значимый эффект. 
К настоящему времени в системе научных знаний в сфере теории и методики физической культуры накоплен достаточно внушительный знаниевый фонд определения ценностного потенциала физической культуры [14-19 и др.]. Тем не менее, несмотря на высокую социальную значимость имеющихся в литературе знаний, выявляется, на наш взгляд, проблема представления системной и уточненной версии ценностей физической культуры с деятельностной (процессуальной) и результативной характеристикой в отношении «окультуривания» биосоциальной при-
Ценности физической культуры: структура, характеристика

роды (человека) личности; становления ее (его) двигательных и личностных потребностей и способностей, отражающих сущностные характеристики ФКЛ и взаимосвязь ФКЛ с иными видами - компонентами базовой культуры человека.

Исходя из того, что культура явно проявляется в материальной, духовной и художественной сферах социума [4], всю совокупность ценностей физической культуры следует представить соответственно группами материальных, духовных и художественных ее ценностей (рис. 1).

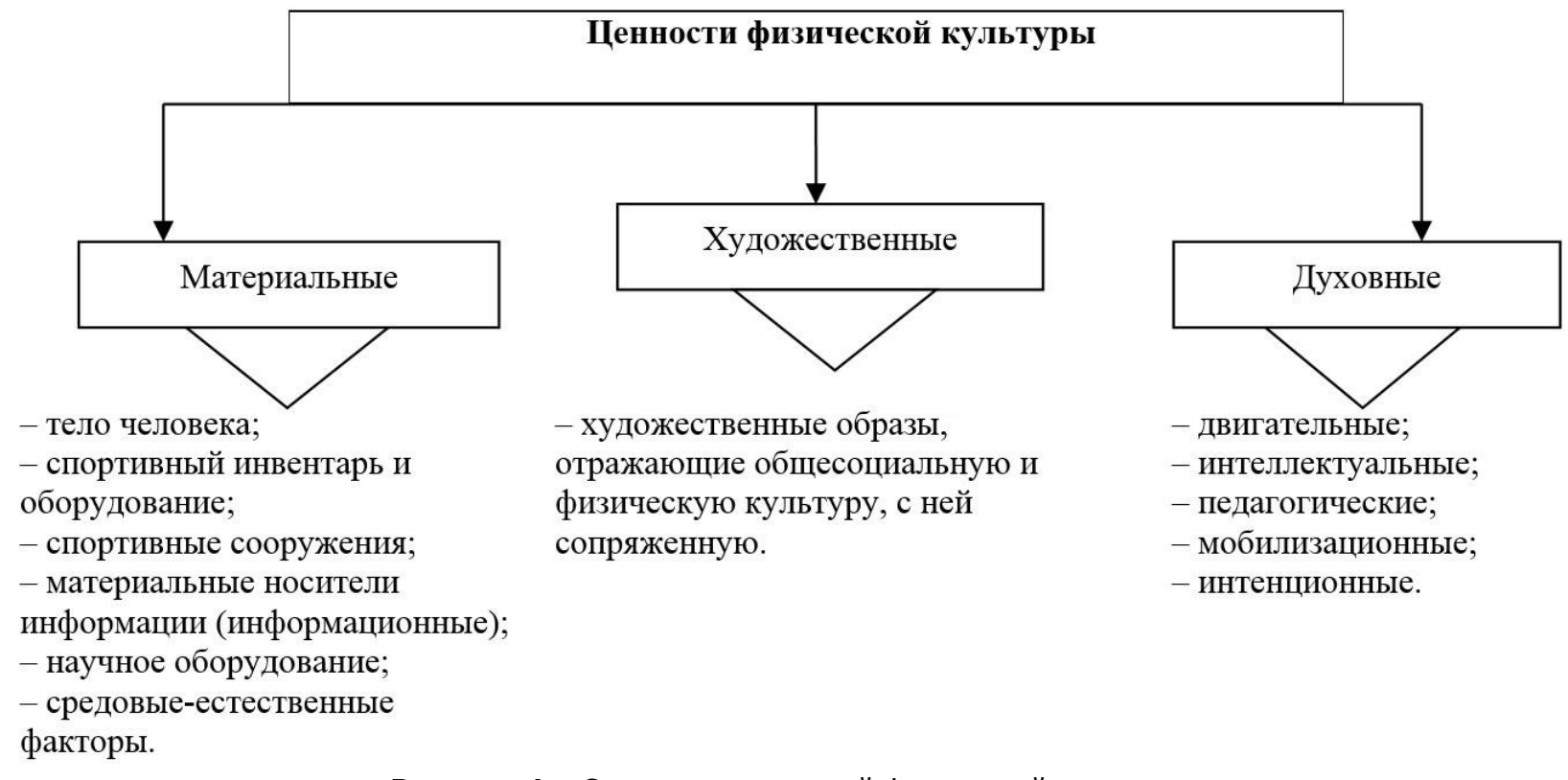

Рисунок 1 - Структура ценностей физической культуры

Тело человека следует считать основной материальной ценностью физической культуры в связи с тем, что оно есть принадлежность к Homo sapiens и уже есть проявление культуры (тело как отражение общесоциальной, человеческой культуры) и культуры именно физической (как материальной основы для потенциальных и реальных целенаправленных воздействий для становления «духа» через «окультуривание» тела); именно тело есть предмет целенаправленного его «окультуривания» за счет двигательных ценностей и прежде всего в части физического развития (в отношении соматометрических и соматоскопических показателей); воспитания двигательных способностей, необходимых и достаточных для жизнеобеспечивающей, социальной и физкультурной практики. Таким образом, тело следует понимать и воспринимать как материальный биологический объект становления и формирования ментальности и социализированности человека, его духовности. Ценность инвентаря и оборудования проявляется, прежде всего, в их многообразии и обеспечении комфортного, эмоционального и привлекательного сопровождения процесса использования двигательных ценностей в сколь избирательности, столь и полифункциональности воздействия преимущественно на двигательную (телесную) сферу человека в процессе физкультурно-спортивной деятельности. Основной результат от освоения этих ценностей - сформированность потребностно-мотивационной и психоэмоциональной сферы личности; ее направленности на физкультурное совершенство- вание и самосовершенствование, модернизацию условий личностной и социальной жизнедеятельности.

Cпортивные сооружения как неотъемлемый атрибут освоения физической культуры представлены в широком диапазоне различных спортивных сооружений (независимых от средовых факторов, различной функциональности и степени сложности и насыщенности оборудованием - «комплексы в комплексе»). Спортивные сооружения - своеобразный «очаг» присвоения и распространения, трансляции практически всей совокупности ценностей физической культуры; фактор «притяжения» к физической культуре через удовлетворение, главным образом, потребностей человека в комфортном освоении духовных ценностей физической культуры, эмоциональном «насыщении», общении, досуговой (рекреационной) деятельности.

Материальные носители информации (отражение духовных ценностей физической культуры) представлены, прежде всего, средствами массовой информации (печатная и видеопродукция различного содержания и направленности). Основное предназначение материальных носителей информации восполнение (скорее и чаще - приобретение) системы научных знаний (общих и специальных), относящихся к различным проявлениям физической культуры: во-первых, ее предметно-ценностной составляющей (как социального явления), во-вторых, с деятельностной ее характеристикой (все процессы, обеспечивающие ее освоение) и, в - третьих, результативной составляющей (совокупность и характеристика эффектов - результатов ее освоения). При этом 
основной признак знаниевой составляющей носителей информации - научность, достоверность, документализм и реальность отображаемых сведений, их направленность на удовлетворение потребности личности в самообразовании в сфере физической культуры, на достижение основных результатов, связанных с освоением физической культуры, и иллюстрацию их значимости для личностной и социальной практики. В числе значимых информационных ценностей, зарегистрированных на различных материальных носителях, находится информация о роли ценностей физической культуры в сохранении и укреплении здоровья, что решает задачу пропаганды здорового стиля жизни, вовлечение в процесс освоения физической культуры. Таким образом, информационные ценности физической культуры способствуют формированию интеллектуальной (познавательной) культуры человека, удовлетворяют потребность личности в утолении «информационного голода», эмоциональном насыщении; формируют духовные мотивы (направленность на физическое самообразование, самосовершенствование; успешное преобразование и трансляцию физической культуры в различные сферы человеческой деятельности).

В воспроизводстве физической культуры особо значимы ценности научного оборудования, позволяющие получить новые знания о функциональном потенциале физической культуры в воспроизводстве культуры общества и личности. Именно за счет специального научного оборудования осуществляется диагностика различных двигательных и личностных способностей; обработка (оперативная, пролонгированная) результатов изменения в процессе физкультурной деятельности различных систем и функций человека (особенно в практике спортивной подготовки). При этом полученные научные сведения о человеке - субъекте освоения физической культуры - обеспечивают оптимизацию управления системами формирования востребуемых состояний человека в процессе освоения физической культуры и спортивной подготовки.

Особую группу материальных ценностей составляют средовые-естественные факторы (бароявления, солнечная радиация, физико-химический состав воздуха и воды, их тепловые и динамические характеристики), которые имеют сколь самоценностное значение в сохранении и укреплении здоровья (изначально все-таки более физического здоровья и, прежде всего, функциональных систем и адаптированности), столь и эффект «усиления» от использования духовных ценностей (в частности, двигательных и педагогических). С известной долей условности к этой группе ценностей можно отнести и некоторые гигиенические факторы - ценности (к примеру, гигиена мест занятий, досуга, профессиональной деятельности и т.п.), использование которых - залог и предпосылка сохранения работоспособности, профилактики заболеваний. Освоение этих ценностей обеспечивает (в самом общем смысле) становление культуры жизни и деятельности человека (в быту, производстве); сущностных характеристик здоровья (физический компонент и связанные с ним психический и социальный); привлекательность и эмоциональность процесса освоения физической культуры во взаимосвязи с природой.
Заканчивая представление материальных ценностей физической культуры, следует отметить, однако, что они есть отражение и «опредмечивание» ценностей духовных, так как появление любой материальной ценности есть изначально «работа» интеллекта, духа человеческого, отражения и проявления духовной культуры социума [6]. Основное же предназначение материальных ценностей - более целенаправленное использование во благо человека ценностей духовных; обеспечение дальнейшего прогресса в развитии физической культуры и ее ценностного духовного потенциала; становление потребностномотивационной сферы личности в физкультурном самосовершенствовании.

Отдельного рассмотрения требуют художественные ценности физической культуры как отражения и «слитности» материальных и духовных ценностей [4]. Следует полагать, что, во-первых, эта группа ценностей имеет место быть (коль скоро есть художественная сфера существования культуры вообще) и, во-вторых, отражает художественное выражение совокупности всех иных ценностей физической культуры, сопряженных с общесоциальными.

Сам факт существования различных материальных носителей, иллюстрирующих красоту человеческого тела (скульптур, статуй, фотоснимков и т.п.), подтверждает их художественность, отражение как общесоциальной культуры, так и культуры физической. При этом различные художественные произведения, отражающие образы человека спорта, своеобразные отношения и взаимоотношения в сфере физической культуры, несут (помимо «красоты тела») и явно выраженный духовный потенциал («красоту духа»), проявляющийся в нравственности, гражданственности, эстетике, этике и т.П. спортивного поведения и взаимоотношений. С освоением художественных ценностей достигается удовлетворение потребности человека в эстетическом наслаждении; эффективное формирование нравственной, эстетической и гражданской культуры личности.

Однако наибольший эффект на процессы восполнения ценностей общесоциальной и физической культуры (как социальных явлений), воспроизводства человека культуры, личности и физической культуры личности оказывают духовные ценности физической культуры.

Двигательные ценности представлены модельными формами («надбиологическими», окультуренными естественными («биологическими») физических упражнений, освоенность которых создает и характеризует модельные параметры двигательной подготовленности, отражающей, в свою очередь, качественно-количественные показатели (характеристики) двигательных качеств (и сопряженных с ними способностей) и технической подготовленности (качество-количество сформированных жизнеобеспечивающих и физкультурно-спортивных двигательных умений и навыков).

Таким образом, двигательные ценности «ответственны» за становление моторной (двигательной) сферы личности (на основе создания «двигательной» базы, двигательного опыта), за реализацию иных форм двигательной физкультурной активности; за подготовку к различным видам моторной деятельно- 
сти (бытовой, производственной, досуговой) и служат для удовлетворения потребностей человека в их рационализации, экономизации; общей и частной эффективности.

Важно при этом, что двигательная подготовленность от освоенности двигательных ценностей должна носить самодостаточный характер (удовлетворяющий личность), отражать готовность человека к наиболее рациональному выполнению двигательных (моторных) актов в различной двигательной деятельности, с легкостью (с «избытком») обеспечивать разнообразную двигательную деятельность сообразно стилю жизни.

Интеллектуальные ценности представлены совокупностью научных знаний в сфере физической культуры (как результат теоретических и эмпирических исследований), зарегистрированных в научно обоснованных теориях как высшей формы организации знания. Кроме того, это масштабные знания о методологических основаниях ее познания и организации на этой основе физкультурно-спортивной деятельности; принципах использования и построения процессов освоения физической культуры; средствах наиболее эффективного становления и формирования (преобразования) характеристик биосоциальной природы личности (сколь в двигательном, столь и в личностном отношении); методах, обеспечивающих эффективную трансляцию ценностей физической культуры в личность и социум; формах организации физкультурно-спортивной деятельности по освоению содержания физической культуры. Основной же результат от освоенности этой группы ценностей сформированность интеллектуальной (познавательной) культуры личности в части познания способов физкультурного самообразования в личностном и двигательном отношении в целях успешной социализации; системы ценностных ориентаций человека в сфере общесоциальных и физкультурно-спортивных ценностей. Эти знания способствуют комплексному совершенствованию сущностных характеристик личности и ее физической культуры. Важно понимать, что интеллектуальные ценности физической культуры распространяются в полной мере на все ее виды (физическое образование, физическая рекреация и реабилитация, спорт, адаптивная и профессиональная физическая культура). Характерно, что интеллектуальные ценности физической культуры существенно взаимосвязаны со знаниями из различных сфер (отраслей) познания и деятельности человека, изначально позволяющие наиболее полно познать биосоциальную сущность человека и эффективно «употреблять» ценности физической культуры в направлении его преобразования; полностью (масштабно и глубоко) использовать ее потенциал в становлении человека культуры.

Педагогические иченности физической культуры «порождение» интеллектуальных ценностей, являются их своеобразным «продолжением». Таким образом, педагогические ценности есть наиболее эффективные способы трансляции ценностей физической культуры «в личность» (по своей сути - образовательные), выработанные на основе знаний, полученных по результатам теоретических научных ис- следований, эмпирических данных, практического опыта. Так, в частности, к педагогическим ценностям следует отнести многочисленные теории, технологии и методики организации и реализации физического образования и спортивной подготовки; оздоровления людей и организации их рекреационной деятельности; физической (отчасти и психической и социальной) реабилитации, адаптивной физической культуры и т.п. Кроме того проявлением педагогических ценностей являются разработанные методологические основания исследования и «применения» физической культуры, методические направления, методы и частные методические приемы педагогического воздействия на становление различных частных двигательных и личностных потребностей и способностей. Таким образом (в самом общем смысле) педагогические ценности отражают методологические основания физической культуры (всех уровней методологии, в большей мере частнонаучный и технологический). Интегральным результатом освоения этой группы ценностей физической культуры является подготовленность обучающегося к разработке программ физкультурного самосовершенствования, творческому преобразованию и использованию ее ценностей для удовлетворения различных потребностей, связанных с физической культурой и воспитанию (коррекция) совокупности способностей (двигательных, личностных), «зависящих» от нее.

Существенное значение для теории и практики освоения физической культуры имеют ее мобилизационные изенности, которые представлены специально созданными различными видами прикладной физкультурно-спортивной деятельности, отвечающими требованиям специальной подготовки человека к конкретным видам деятельности и известной коррекции личностных и двигательных качеств, и эффект от освоения которых необходимо рассматривать в двух главных, на наш взгляд, аспектах:

1. Состояние сформированности прикладных двигательных и личностных способностей, отражающих готовность к практике общесоциальной и конкретной (преимущественно профессиональной) жизни и деятельности. В таком контексте речь идет о становлении в ходе физкультурно-спортивной деятельности прикладных личностных и двигательных качеств, свойств и функций личности, которые необходимы ей для успешной социализации, участия в процессе различных видов деятельности (конкретнее - в общении, труде, игре, образовании и т.п.). Так, в ходе освоения мобилизационных ценностей формируются сущностные характеристики и качества нравственной, эстетической, гражданской и т.п. культуры личности; совокупность «потребных» для личности двигательных качеств, которые значимы для практики жизнедеятельности конкретного человека (группы людей) и которые, несомненно, востребованы практикой повседневной и, главное, образовательной и профессиональной деятельности.

2. Сформированность двигательных и личностных способностей, отражающих «организационные» начала человека, его «собранность», социальную активность, «избыточный» уровень готовности противостоять неблагоприятным факторам жизни и дея- 
тельности (начиная с неблагополучной экологии и заканчивая психогенными факторами). В этом случае и с освоением мобилизационных ценностей формируются характерные признаки здорового стиля жизни, настойчивость и терпеливость, воля и умение управлять эмоциями, умение противостоять неудачам и «срывам», готовность к действиям в экстремальных ситуациях с сохранением психоэмоциональной устойчивости и т.п.

Таким образом, с освоением мобилизационных ценностей (в нашей интерпретации их следует понимать как «мобильные ценности переноса») достигается эффективный «перенос» двигательных и личностных потребностей и способностей, сформированных в физкультурно-спортивной деятельности, на реальную практику жизни и деятельности, обеспечивая тем самым удовлетворение потребности социума и личности в подготовленности к реалиям жизни и успешной социализации.

Интенционные ценности физической культуры есть духовное проявление стремления, предрасположенности, внимания к проблемам функционирования и освоения физической культуры [8, с. 419]; проявляются в направленности социального сознания на физическую культуру как ценность, значимую для общества и личности; отражают, главным образом, фундаментальное отношение социума к физической культуре. Именно интенционные ценности «задают» структуру системы целеполагания в отношении развития физической культуры, ее направленного использования. При этом интенционные ценности проявляются (в общем) в государственной политике в отношении физической культуры: финансирование, строительство, наука, специальное образование (подготовка кадров) и т.п. Интенционные ценности физической культуры на уровне общественного сознания проявляются в престижности ЗОЖ, его «модности», популярности спорта, отношении к национальным и интернациональным видам спорта, факторам «риска» и т.п. Следовательно, к интенционным ценностям физической культуры следует отнести характер мотивации (биологические, социологические, духовные); иерархию сформированных общесоциальных ценностей и место в ней физической культуры; направленность социума и личности на занятия физическими упражнениями и спортом. Таким образом, реализацию интенционных ценностей следует осуществлять в ходе известной интенциональности физического образования, означающего его направленность на становление потребностно-мотивационной сферы человека на физическую культуру; систему ее ценностных ориентаций и направленности на физкультурное самосовершенствование. Критериальными показателями освоенности этой группы ценностей являются: ценностное отношение человека и общества к физической культуре, потребности и мотивы в физкультурном становлении (отдельного человека и социальной группы), включенность в процессе освоения физической культуры.

Таким образом, представленные структура и процессуально-результативная характеристика ценностей физической культуры определяют, во-первых, их номенклатуру и, во-вторых, ценностно-функциональный потенциал физической культуры в станов- лении, совершенствовании и формировании базовой и физической культуры личности. Тем не менее методологическим основанием направленного использования физической культуры для достижения образовательных, «культурных» эффектов в отношении социума и личности является оптимальное соотношение используемых ценностей физической культуры в конструировании образовательных систем и определении содержания физкультурно-спортивной деятельности.

\section{СПИСОК ЛИТЕРАТУРЫ:}

1. Краевский В.В. Методология педагогики: новый этап. М.: Академия, 2008. 400 с.

2. Коджаспирова Г.М., Коджаспиров А.Ю. Словарь по педагогике. М.: ИКЦ «МарТ»; Ростов-наДону: Издательский центр «МарТ», 2005. 448 с.

3. Библер В.С. От наукоучения - к логике культуры: два философских введения в XXI веке. М.: Наука, 1991. 384 с.

4. Каган М.С. Философия культуры. СПб.: Лань, 1996. $253 \mathrm{c.}$

5. Каган М.С. Философская теория ценности. СПб.: Петрополис, 1997. 205 с.

6. Злобин Н.С. Культура и общественный прогресс. М.: Наука, 1998. 303 с.

7. Маркарян Э.С. Теория культуры и современная наука: логико-методологический анализ. М.: Мысль, 1983. 284 с.

8. Всемирная энциклопедия: Философия / гл. ред. и сост. А.А. Грицанов. М.: АСТ, Минск: Харвест, Современный литератор, 2001. 1312 с.

9. Гессен С.И. Основы педагогики. Введение в прикладную философию. М.: Школа-пресс, 1995. 394 c.

10. Курамшин Ю.Ф. Теория и методика физической культуры. М.: Современный спорт, 2003. 464 с.

11. Круцевич Т.Ю. Теория и методика физического воспитания. Киев: Олимп, 2003. Т. І. 391 с.

12. Коровин С.С. Теория и методика формирования физической культуры личности. Оренбург: Издво ОГПУ, 2005. 72 с.

13. Коровин С.С. Введение в теорию и дидактические основания физической культуры. Оренбург: Изд-во ОГПУ, 2006. 132 с.

14. Бальсевич В.К., Лубышева Л.И. Физическая культура: молодежь и современность // Теория и практика физической культуры. 1995. № 4. С. 5-11.

15. Быховская И.М. «Человек телесный» в социокультурном пространстве и времени. М.: ФОН, 1997. 209 c.

16. Петьков В.А. Теоретические основы и прикладные аспекты формирования физической культуры личности в системе непрерывного образования: автореф. дис. ... д-ра пед. наук. Краснодар, 1999. $46 \mathrm{c}$.

17. Пономарчук В.А. Человек в мире спорта: проблемы становления личности. М.: ФИСО, 1994. $118 \mathrm{c}$.

18. Соловьев Г.М. Педагогическая технология формирования физической культуры личности студента: автореф. дис. ... д-ра пед. наук. М., 1999. 34 с.

19. Лубышева Л.И. Социология физической культуры и спорта. М.: Академия, 2001. 240 с. 


\section{VALUES OF PHYSICAL CULTURE: STRUCTURE, CHARACTERISTICS}

\section{(C) 2017}

Korovin Sergey Semenovich, doctor of pedagogical sciences, professor of Theory and Methodology of Sports, Adaptive Physical Culture and Medico-Biological Foundations of Physical Education Department Maloroshvilo Lilia Nailievna, candidate of pedagogical sciences, associate professor, head of Physical Culture Department Orenburg State Pedagogical University (Orenburg, Russian Federation)

Abstract. Target development and justification of established theories, technologies, and structures of educational systems is the formation of cultural characteristics of the individual at all stages of continuous education, which reflects the mentality of society and the state (as a result) - development of the value-oriented «overbiological» programs of human activities, knowledge, abilities and skills of their practical and creative use. It is very important to develop components (their characteristics) of the individual basic culture, which include moral, aesthetic, labor, civil, intellectual (cognitive) and physical cultures. Nowadays, the structure of physical culture values can be represented by a group of material (the human body, sports equipment, sports facilities, mass media, scientific equipment, environmental - natural factors), spiritual (physical, intellectual, pedagogical, mobilization, intention) and artistic (a set of artistic images and works that reflects the values of the material and spiritual spheres of the society) values. The optimum ratio of the used physical culture values is believed to ensure the quality of the content of sports activity and as a consequence - the development of culture among students.

Keywords: culture; education; physical culture; physical education; personality development; basic culture components; physical culture of personality; physical culture values structure; characteristic of material; spiritual and artistic values of physical culture.

\section{ПРОФЕССИОНАЛЬНОЕ ОБЩЕНИЕ НА ИНОСТРАННОМ ЯЗЫКЕ: НЕКОТОРЫЕ ВОПРОСЫ ПРОЕКТИРОВАНИЯ ПРАКТИКУМА ДЛЯ БАКАЛАВРОВ}

\section{(C) 2017}

Малова Наталья Владимировна, кандидат педагогических наук, доцент кафедры иностранных языков Самарский государственный институт культуры (2. Самара, Российская Федераиия)

\footnotetext{
Аннотация. В статье обсуждается одна из таких актуальнейших задач подготовки современного специалиста, как формирование его готовности к ведению профессиональной коммуникации на иностранном языке. Запросы практики закономерно находят свое отражение в формировании учебных планов и программ высшего профессионального образования. Автором демонстрируется актуальность поставленной задачи в связи с постоянно изменяющимися требованиями к осуществлению иноязычных профессиональных коммуникаций с акцентом на их компьютерно-опосредованную часть. Для этого обозначаются два основных подхода к организации обучения студентов в вузе: изменение структуры, содержания, методики учебной дисциплины «Иностранный язык» и разработка новых дисциплин учебного плана. В рамках второго подхода достаточно подробно рассмотрен процесс проектирования учебно-методического комплекса для курса-практикума профессионального общения на основе процессного подхода. Описание этапов снабжено конкретными примерами разработки для профиля подготовки «Звукорежиссура культурно-массовых представлений и концертных программ». В статье подчеркивается важность использования профессиональных навыков будущих специалистов для повышения эффективности учебного процесса, в частности, разработки авторских аудио- и видеоматериалов. Показано, что разработанный в соответствии с предлагаемой схемой практикум для аудиоинженеров успешно используется в учебном процессе Самарского государственного института культуры.

Ключевые слова: методическое проектирование; иностранный язык; подготовка бакалавров; интерактивное обучение; тезаурус студента; ситуации профессионального общения; видеоконтент; подготовка звукорежиссера; практикум профессионального общения на иностранном языке; аудиоконтент; сценарий профессионального общения; контекстный подход.
}

Глобализация современного мира, информатизация социума и взрывной рост доступности современных информационно-коммуникационных технологий закономерно трансформирует иноязычное профессиональное общение из специфической в повседневную задачу. Консультации по скайпу с производителями импортного оборудования, изучение многочисленных мануалов и технических руководств, общение со службами технической поддержки - вот далеко не полный перечень ситуаций, в ко- торых современный специалист применяет свои навыки общения на иностранном языке. Запросы практики закономерно находят свое отражение в формировании учебных планов и программ высшего профессионального образования. Особую важность при этом приобретает проектирование и корректная реализация интерактивного обучения иностранному языку в контексте будущей профессиональной деятельности выпускников-бакалавров неязыкового вуза [1]. 